\title{
Evidence-based medicine and the journal club: a cross-sectional survey of participants' views
}

\author{
James P. Warner and Michael King
}

"Journal clubs are dying or dead" (Sackett et al, 1997). Although this view is gaining ground, journal clubs remain a fundamental part of postgraduate education, both from the point of view of continuing medical education for consultants and the education of trainees. There are problems with the traditional journal club format: the paper may be selected ad hoc and may not be the most suitable to cover the topic in question; the trainee may have no say in the choice of paper, not know why the paper has been chosen and have little interest in the topic; often, trainees précis a paper, and offer an unstructured and poorly performed critique; trainees get no experience of reviewing a question or undertaking a literature search.

For these reasons, the whole process can be very boring for the audience and presenter alike, and limited in terms of learning. In an attempt to overcome these difficulties, an alternative approach would be to adopt the evidencebased medicine (EBM) paradigm (Gilbody, 1996; Sackett et al, 1997). Evidence-based medicine, defined as the conscientious, explicit and judicious use of current best evidence in making decisions about the care of individual patients (Sackett et al, 1996), has been suggested as a new approach to teaching the practice of medicine (Evidence-Based Medicine Working Group, 1992). From the point of view of an academic programme, the EBM approach could involve integrating the case conference with the journal club; the paper presented at the latter chosen to address a question or topic arising from the case.

\section{The EBM approach}

The weekly postgraduate meeting in our department used to begin with a one-hour case presentation, followed by an unrelated journal club. These meetings are generally attended by around 30 people including consultants, trainee psychiatrists and medical students. In an attempt to enliven the programme, and to offer a non-threatening introduction to the principles of EBM, we changed the format of these meetings. Over two terms we alternated weekly conventional case conference/journal club meetings with those of an evidence-based format where the journal presentation was linked with the immediately preceding case conference.

When preparing for the EBM sessions, the presenters of the case and the journal were invited to meet with a member of the academic staff at least a week beforehand. A question raised by the case conference was identified by the trainees as the focus of the EBM session. Trainees were offered guidance about literature searching. statistical analysis and critical appraisal techniques. Examples in these sessions so far have included: Is cognitive-behavioural therapy useful in an older depressed patient?; What is the evidence to support the use of clozapine in a patient with treatment resistant schizophrenia?; Does single photon emission tomography aid the diagnosis of Alzheimer's disease? Many articles reviewed have been related to therapy, but could address other issues, for example, the use of a diagnostic test. the utility of a meta-analysis, or the prognosis of an illness.

Once a question relevant to the case conference had been decided the EBM session presenter undertakes a literature search using Medline, with the help of our librarian if necessary. Key papers are identified and one or two selected for critical assessment using the guidelines outlined in Sackett et al (1997). The paper(s) are then presented at the journal club.

\section{Assessment of EBM approach}

We took advantage of the phased introduction of EBM presentations to assess the participants' 
attitudes to each of the presentation formats. A brief questionnaire using a four-point Likert scale was designed to assess attitudes to both the new and old formats. We sought information on whether the respondent preferred the new or old format and whether the EBM approach was approprlate for the academic meeting. The sample were asked whether, as a result of the new format, they had changed their approach to reading journal articles, found research more daunting or had altered their approach to addressing difficult clinical problems. We were also interested to identify whether participants preferred to have the question, or educational prescription, decided by the presenters in advance of the meeting and presented immediately after the case presentation, or whether it should be decided by the audience of the case conference and discussed the following week. The former provides continuity for the audience, the latter gives the audience ownership of the question posed. However, the audience to which it is presented may be substantially different to that which set the question.

The questionnaire was sent to all consultant and junior staff who had attended the academic programme during the change-over period. Of the 34 questionnaires mailed, 27 (79\%) were returned. Only four (15\%) were returned by consultants and this precluded comparison of attitudes between them and trainees. Scores were dichotomised. Most of the responders to our questionnaire felt that the new format had not only improved their critical appraisal of papers, but had also changed their approach to difficult clinical problems (Table 1). Seventythree per cent of the respondents in our survey preferred the question set in advance and presented on the same day as the case presentation.

Evidence-based medicine is an increasingly popular paradigm, not only in day-to-day medical practice, but also in education. The EBM approach requires acceptance that clinical knowledge has a short 'shelf-life', demands familiarity with information technology to conduct literature searches and an ability to assess carefully the applicability of journal articles to one's own clinical practice. Intuitively, many clinicians may feel threatened by this approach.

We encountered some problems in introducing EBM to the academic programme. In particular, trainees have had some difficulty in identifying suitable papers for the questions posed. This has been the case even when the questions have appeared straightforward, for example, do steroids cause psychosis? The main reason for this is that only one database (Medline) was usually available to the trainees. A second problem has been obtaining the papers identified by the literature search. Despite good library facilities, some papers take over a week to obtain, leaving the presenter very little time to prepare.

The transition to EBM has been facilitated by a number of factors. One person, who has some experience of the process, took on the responsibility for the academic programme, offered guidance to trainees and taught some of the principles. This was time-consuming initially, but as trainees have become more familiar with the format, less input has been necessary. Good statistical support and library search facilities have also been important to the success of this venture.

Although few consultant staff replied to the questionnaire, our impression is that most have welcomed the changes. Nevertheless, many clinicians are resistant to EBM and may be reluctant to participate in the process. This is likely to become less of an issue as the process gains acceptance. In the interim, a phased approach along the lines of our introduction may help to allay the anxieties of some staff.

Departments may have case conferences and journal clubs on different days and it is not necessary to combine these events as we have done. The journal club can become evidencebased by collecting a bank of clinical scenarios for trainees to select and work on. The principal components of EBM; setting a question, undertaking a literature search and critically appraising the literature, will be preserved.

This small survey indicated that using the EBM format in the academic programme has

Table 1. Results of the questionnaire to assess utility, acceptability and impact of EBM journal club compared with traditional style of journal club

\begin{tabular}{lll}
\hline & $\begin{array}{l}\text { Agree or strongly } \\
\text { agree }\end{array}$ & $\begin{array}{l}\text { Disagree or strongly } \\
\text { disagree }\end{array}$ \\
\hline The EBM format: & & $12 \%$ \\
has improved my critical appraisal of articles & $88 \%$ & $78 \%$ \\
has made clinical research more daunting & $22 \%$ & $19 \%$ \\
may change my approach to difficult clinical problems & $81 \%$ & $0 \%$ \\
is appropriate for the academic programme & $100 \%$ & $19 \%$ \\
is preferable to the traditional journal club & $81 \%$ & \\
\hline
\end{tabular}


provided an introduction to the process that appears to be acceptable to most users. The new style of journal club has proven popular with the attenders at our academic meeting and appears to confer several advantages over the traditional style. Our academic programme is now fully EBM orientated.

\section{References}

EVIDENCE-BASED MEDICINE WORKING GROUP (1992) Evidencebased medicine. Journal of the American Medical Association, 268. 2420-2425.
GILBODY. S. (1996) Evidence-based medicine. An improved format for journal clubs. Psychiatric Bulletin, 20, 673675.

SACKETT, D. L.. RichardSON. W. S., ROSEnBERG, W., et al (1997) Evidence-Based Medicine. New York: Churchill Livingstone.

- Rosenberg. W. M. C., Muir-Gray, J. A., et al (1996) Evidence-based medicine: what it is and what it isn't. British Medical Journal, 312, 71-72.

*James P. Warner, Lecturer and Michael King, University Department of Psychiatry, Royal Free Hospital School of Medicine, Pond Street, London NW3 2QG; e-mail: warner@rfhsm.ac.uk

*Correspondence

\section{Seminars in the Psychiatry of Learning Disabilities}

\section{Edited by Oliver Russell}

This volume is both an up to date account of recent advances in the field of learning disabilities and a practical guide to the diagnosis and treatment of psychiatric disorder. Chapters on the classification of psychiatric disorders in people with learning disabilities, the epidemiology of intellectual disability and the diagnosis of psychiatric disorder are followed by more detailed accounts of autism, behavioural phenotypes and communication disorders. Psychiatric disorders are covered in the latter part of the book, including discussions on behavioural interventions, counselling and epilepsy. The book concludes with a review of forensic aspects of psychiatric management and treatment. 1997, 288pp, ISBN $0901242021, £ 15.00$

The College Seminars Series and other Gaskell publications are available from Booksales,

Publications Department, Royal College of Psychiatrists, 17 Belgrave Square, London

SW1X 8PG (Tel. +44(0)171 235 2351, extension 146). The latest information on College publications is available on the INTERNET at: http://www.demon.co.uk/rcpsych/ 